\title{
The Relationship Between WeChat Use by Chinese Urban Older Adults Living Alone and Their Subjective Well-Being: The Mediation Role of Intergenerational Support and Social Activity
}

\author{
Li Song' \\ Yan $\mathrm{Ge}^{2}$ \\ Xuyang Zhang ${ }^{3}$
}

'Institute of Arts and Humanities, Shanghai Jiao Tong University, Shanghai, 200240, People's Republic of China; ${ }^{2}$ Institute of Psychological and Behavioral Science, Shanghai Jiao Tong University, Shanghai, 200240, People's Republic of China; ${ }^{3} \mathrm{School}$ of Humanities, Shanghai Institute of Technology, Shanghai, 201418, People's Republic of China
Correspondence: Li Song Institute of Arts and Humanities, Shanghai Jiao Tong University, Shanghai, 200240,

People's Republic of China

Tel +86-18585059965

Fax +86-2I-6293280I

Email rediscovering@163.com
Purpose: WeChat is China' biggest social media platform. In addition to instant messaging, it has a great many useful functions that can help Chinese citizens adapt to an increasingly digitized society. This study aimed to examine the effect of WeChat use on the subjective well-being (SWB) of Chinese older adults living alone, and how the effect could occur.

Participants and Methods: A total of 415 Chinese older adults living alone participated in the survey. Participants filled out questionnaires (scales) measuring their SWB, proficiency in WeChat use, social activity levels and self-esteem respectively. Mean scores of SWB were used to determine the difference in SWB between the users and non-users, and correlation test was performed to find out the association between proficiency in WeChat use and SWB among the users.

Results: The mean score of WeChat users was 34.68 (SD = 7.301), significantly higher than that of the non-users, which was $32.73(\mathrm{SD}=7.168)(t=2.741, p=0.006)$. Among the users, the more proficient in WeChat use one was, the higher their SWB score $(r=0.458, p<0.01)$. The results combined to demonstrate that WeChat use has a positive effect on the SWB of Chinese older adults living alone. The findings also showed that the increase in SWB was obtained through the mediation of intergenerational support and social activities.

Conclusion: This study suggests that WeChat use by Chinese older adults living alone could increase their intergenerational support and social activities; the increased intergenerational support and social activities then enhance the SWB of Chinese older adults living alone.

Keywords: WeChat, older adults, subjective well-being, intergenerational support, social activity, self-esteem

\section{Introduction}

The influence of social advances and the ensuing lifestyle changes on individuals is an integral part of subjective well-being (SWB) research. Since the turn of the century, the digitization of society, fueled by the popularization of the Internet and social media, has increasingly become a prominent characteristic of modern China, as well as of many other nations. Researchers, witnessing the social changes brought about by digitization, are becoming to give more thought to if, and how, digital technology, particularly social media, can have an impact on people's SWB. ${ }^{1}$

In China, one particular social media platform is almost unanimously believed to have played the biggest role in the changes toward an increasingly digital-based 
way of life. This social media platform is WeChat. Launched in 2012 by Chinese tech behemoth Tencent, and gradually gaining great popularity ever since, WeChat crossed the threshold of one billion users in 2018. Now, WeChat is indisputably the biggest social media in China, with 1.24 billion monthly active users. ${ }^{2}$

Unlike Weibo, China's equivalent of Twitter, whose major function is information dissemination, ${ }^{3}$ WeChat has many other useful functions, in addition to instant messaging, such as video calling, paying, ride hailing, and hotel booking. It is virtually a "one-stop shop for its users", "a digital life platform for the Chinese", 5 or "China's app for everything". 6 WeChat's success has attracted attentions from its international counterparts. According to a report in The Economist, Zuckerberg "seems keen to turn Facebook into a Western version of WeChat". ${ }^{7}$ New York Times also pointed out that WeChat's success "has implications for Google, Twitter and many others, as well as Facebook."

Due to its powerful functionality and wide use, researchers have noticed WeChat's potential to exert influence on people's interpersonal relations, day-to-day life, work, and, ultimately, well-being.

The existing literature on the relationship between WeChat use and users' SWB is primarily focused on younger groups, especially college students. Research on the elderly is scant. This may be attributed to the facts that (1) younger samples, particularly college students, are much easier to recruit than older adults, and (2) older adults are typically late adopters of tech products. In 2016, there were approximately 7,680,000 older WeChat users (aged 55 and above), accounting for only $1 \%$ of the user population. ${ }^{9}$ In 2018 (Tencent did not release data regarding WeChat's user structure after 2018), the number of older users jumped to $63,000,000$, but still accounting for a small proportion of its user base (6.24\%). ${ }^{10}$

On the other hand, China is fast becoming an aging society. According to the newly released national census data by the China National Bureau of Statistics, as of the end of 2020, China had 264 million people aged 60 and above, accounting for $18.7 \%$ of the total population, up from $13.26 \%$ in $2010 .{ }^{11}$ In urban areas, the percentage is even higher. For example, in Beijing, older adults of that age group account for $19.63 \%$; in Shanghai, it is $23.38 \%{ }^{11}$ At a time when "digitization meets population aging", it is of great importance to explore the influence of WeChat use on the SWB of the elderly.
The current study chose urban older adults living alone as the research subject for three reasons: First, older adults living alone are, in the Chinese context, highly disadvantaged people to whom special attention should be paid; second, with divorce rates rising and more adult children working away from their parents, older adults living alone is very likely to become more prevalent in China; third, WeChat use was the focus of this study, and whether the elderly live with their spouse/child or not is an important factor influencing their SWB. Older adults living alone are more demographically homogeneous, making them better research subjects for the research.

\section{Literature Review}

\section{Factors Influencing the SWB of the Elderly}

SWB is influenced by many factors. For the elderly, and the Chinese elderly in particular, the following factors have been mostly examined by researchers:

1. Health. Much of the fear of aging stems from health concerns. In fact, evidence has shown that healthy older people have significantly higher levels of SWB than those with serious illness. ${ }^{12}$ In addition to the direct effect of illness-related factors, such as pain and impaired mobility, poor health may also indirectly undermine the SWB of the elderly by posing an economic burden. ${ }^{13}$

2. Urban vs Rural. Urban/rural disparities are a prominent Chinese characteristic. Research has shown a wide gap between China's urban and rural areas in terms of economy, environment, infrastructure, and much more. The SWB of the urban elderly is much higher than that of the rural elderly to the extent that it was labeled the "difference between Heaven and Earth". ${ }^{14}$

3. Empty Nest and Living Alone. Research shows that the physiological and emotional wellness of the empty nesters is significantly lower than that of the non-empty nesters. Moreover, the average SWB score among the empty nesters is much lower than that of the non-empty nesters. ${ }^{15} \mathrm{Li}$ et al compared three types of Chinese older adults: Those living with their spouse and children, those living only with their spouse, and those living alone. A total of 2225 older adults in seven Chinese cities were surveyed in the research. The results showed that 
the elderly living alone had the most negative emotions, and their SWB was significantly lower than that of the other two types of older adults. ${ }^{16}$ Literature also showed that compared with those living family members, older adults living alone usually receive less attention and resources from the public or their relatives, ${ }^{17}$ are less likely to adopt health-promoting behaviors, ${ }^{18}$ and selfneglect is pervasive among them. ${ }^{19}$

4. Social Support. Social support is defined as information leading the subject to believe that they are cared for and loved, esteemed, and a member of a network of mutual obligations. ${ }^{20}$ For the Chinese elderly, support from family members, their children in particular, plays the biggest role in determining their SWB, especially when their social connections diminish with retirement. As a result, many studies singled out children's support, also known as intergenerational support, as a prominent factor contributing to Chinese older adults' SWB. Some scholars believe intergenerational support is more important for aged adults' SWB than is social support from outside the family in China, ${ }^{21}$ and compared with western populations, family support has a greater influence on the alleviation of depression among older adults in Asia. ${ }^{22}$

5. Education and Income. Although findings of previous studies around the world showed mixed results, there seemed to be a pattern that, when an individual is in a financially challenged situation, an increase in income can substantially increase their SWB level. When the individual overcomes such financial constraints, the correlation between income and SWB becomes weak. ${ }^{13}$ For example, a survey on 236 older adults in Beijing showed no significant correlation between SWB and income. ${ }^{23}$ On the contrary, Ren et al found that income is a strong predictor of SWB of the rural elderly. ${ }^{24}$ The inconsistency might be explained by the fact that most of the Chinese elderly in rural areas have a much lower level of income, so the impact of income is significant. In contrast, seniors in urban areas enjoy a much higher income level, resulting in the effect of income being considerably less significant than rural seniors. Similar to income, the influence of education level on the SWB of Chinese seniors in urban areas is not significant. ${ }^{23,24}$ To a large degree, this might be because the overall level of education among Chinese older adults is very low. As of 2010, $90.91 \%$ of the Chinese elderly only had junior high school education or below. ${ }^{25}$ Even those who were lucky enough to have had access to higher education during the 1960s and 1970s often found their classes disrupted by the Cultural Revolution.

6. Self-esteem. Self-esteem, also referred to as selfworth, as its name suggests, is a person's overall subjective sense of personal worth or value, or, simply put, how much they appreciate and like themselves. In Western countries where individuality is more appreciated than in the East, self-esteem has long been an essential determinant of a person's SWB. Murrell, Meeks, and Walker found that a high level of selfesteem could ward off depression over time in older adults. $^{26}$ Alaphilippe's study suggested that selfesteem is an important aspect of the adaptive processes at all stages of life, especially in later life, positively associated with the quality of adaptation and SWB. ${ }^{27}$ In recent years, Chinese scholars have been paying more attention to self-esteem when studying people's SWB, and findings also suggest that there is a positive connection between the two. ${ }^{28,29}$

\section{Impact of Social Media Use on SWB}

Although the majority of existing studies on SWB focus on young people, many of the findings can still provide valuable insights and perspectives for studies on the elderly.

Research results were mixed in terms of the relationship between social media use and their users' SWB. Some studies showed that social media use is positively associated with their users' SWB. ${ }^{30-32}$ An explanation of this positive relationship is as follows: As "social animals", having connections with other "social animals" is a basic need of human beings; ${ }^{33}$ good interpersonal relationships are a key element affecting an individual's SWB. ${ }^{34}$ Social media breaks the physical barriers of interpersonal communication and provides an efficient way for interpersonal interaction. It is particularly effective in reinforcing fledgling and distant relationships. As such, social media promotes the establishment and maintenance of interpersonal relationships with unprecedented conveniences, building a sense of belonging for many people. ${ }^{35}$

While the use of social media does facilitate information exchange, some studies found that there is a dark side to it. Holton argued that there are great surpluses of irrelevant information on social media platforms, resulting in 
information overload and increased levels of stress and anxiety among their users. ${ }^{36}$ Even worse, social media overuse could cause a feeling of "not having done anything meaningful", negatively affecting people's emotional state or even leading to a deterioration of mood. ${ }^{37}$

Most people use social media for a range of activities. These activities can be broadly classified into two categories: Active and passive usage. ${ }^{38}$ Active usage usually involves direct interaction with others or searching for specific information. Passive usage refers to the monitoring of other people's lives without engaging in direct exchanges with them. ${ }^{39}$ For example, scrolling through news feeds or looking at others' tweets. According to the "active-passive" framework, researchers suggested that, generally speaking, active use of social media enhances SWB while passive use reduces it. ${ }^{40}$

\section{Research Questions and Hypotheses}

The two basic research questions of the current study were:

1. Does the use of WeChat have an impact on the SWB of the elderly living alone?

2. What is the mechanism by which this effect occurs?

Examining WeChat's features and analyzing the usage pattern of older users, along with existing studies of other social media platforms' impact on their users, we proposed Hypothesis 1 to address research question 1 .

H1: WeChat use is positively associated with the SWB of older adults living alone.

Since our sample consisted of both WeChat users and nonusers, H1 comprises two dimensions: (1) whether there is a statistically significant difference of the SWB (represented by the mean score) between the two groups. (2) within the user group, whether there is a correlation between the older adults' proficiency in WeChat use and their SWB. Accordingly, H1 was further delineated into two sub-hypotheses:

H1a: (between-group): Older adults living alone who use WeChat have a higher SWB level than those who do not use WeChat.

H1b: (within-group): Among the WeChat users, the more proficient one is in using WeChat, the higher their SWB level.
To address research question 2, we drew on existing literature and a pilot investigation (mainly in the form of interviews with older adults on the topic "What changes does using WeChat bring to your life?") and proposed three possible mediators: Intergenerational support, social activity, and self-esteem. As discussed above, existing studies have demonstrated that the three factors are all positively associated with older adults' SWB. It is important to determine whether WeChat use is positively associated with these factors. The corresponding hypotheses are as follows:

$\mathrm{H} 2$ : WeChat use is positively associated with the intergenerational support that older adults living alone receive.

H3: WeChat use is positively associated with the social activity level of older adults living alone.

H4: WeChat use is positively associated with the selfesteem of older adults living alone.

Similar to H1, each of the three hypotheses was further delineated into between- and within-group sub-hypotheses as follows:

H2a: Older adults living alone who use WeChat have a higher level of intergenerational support than those who do not use WeChat.

$\mathrm{H} 2 \mathrm{~b}$ : Among WeChat users, the more proficient one is in using WeChat, the more intergenerational support they receive.

H3a: Older adults living alone who use WeChat have a higher social activity level than those who do not use WeChat.

H3b: Among WeChat users, the more proficient one is in using WeChat, the higher their social activity level.

H4a: Older adults living alone who use WeChat have a higher self-esteem level than those who do not use WeChat.

$\mathrm{H} 4 \mathrm{~b}$ : Among WeChat users, the more proficient one is in using WeChat, the higher their self-esteem level.

These hypotheses, if supported, could be expressed as: WeChat use increases the SWB level of older adults living alone by improving their intergenerational support, social activities, and self-esteem (shown in Figure 1). 


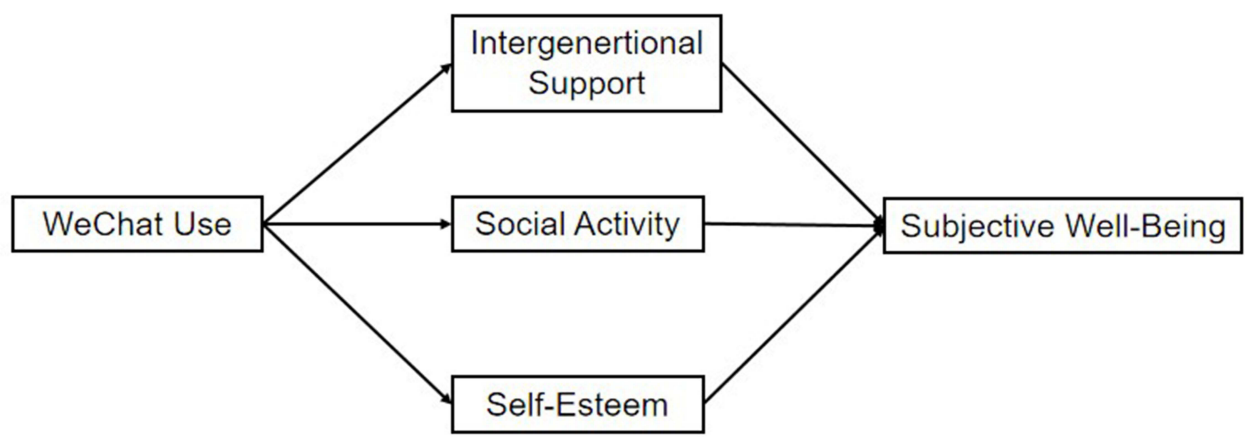

Figure I Research conceptual model.

\section{Materials and Methods}

\section{Participants and Sampling}

Broadly speaking, older adults living alone include those who have not had children (or have lost their children) and those who have adult children but live separately. Since the majority of Chinese elderly, whether living alone or not, are not childless and intergenerational support is potentially a key mediator, the participants of our study were older adults (age 60 or above) living separately from their child who lives in another city. In addition, we set exclusion criteria as follows: (1) Severe chronic illness or physical impairment; (2) major negative life events, such as loss of a close relative; (3) older than 80 , because older adults over 80 , also called "the fourth age", are classified by gerontologists as a group of "biocultural incompleteness, vulnerability, and unpredictability that is distinct from other old age group"; ${ }^{41}$ (4) having more than one child, because having multiple children may cause confusion when filling out the intergenerational support questionnaire. Besides, excluding those who have multiple children could make the sample more demographically homogeneous, potentially increasing the research validity. Since China implemented its one-child policy between the late 1970s and mid-2010s, most urban older adults who meet the age requirement of our survey have only one child. Excluding those having multiple children was not a difficult task.

The survey was conducted between July and October 2020 in Gui Yang, the capital city of Gui Zhou Province in southwest China. A total of 415 participants were recruited by snowball sampling. Eight investigators were employed and trained to conduct the paper-pencil survey. Each participant received a gift with a value of CNY 15 as an incentive to participate. Table 1 shows the demographic data of the sample.

\section{Measurements} Measurement of WeChat Usage

The Questionnaire on WeChat Proficiency proposed by the Tencent Research Institute was used to measure how well the participants use the social media platform. ${ }^{42}$ The original questionnaire is composed of 19 items (WeChat functions), such as "text messaging", "video calling", "posting moments" and "WeChat payment". For each function, there are three evaluation options: "I don't use this function", "I use this function but not proficiently" and "I use this function proficiently" with scores of 0,1 , and 2, respectively. The scores for each item are added to yield an overall score, which indicates the user's proficiency in WeChat. Prior to our survey, we consulted some elderly

Table I Profile of the Participants ( $N=4 \mid 5)$

\begin{tabular}{|l|c|c|c|}
\hline Measure & Items & Frequency & Percentage \\
\hline Gender & Male & 201 & $48.43 \%$ \\
& Female & 214 & $51.57 \%$ \\
\hline \multirow{2}{*}{ Age } & $60-64$ & 188 & $45.30 \%$ \\
& $65-69$ & 169 & $40.72 \%$ \\
& $70-79$ & 58 & $13.98 \%$ \\
\hline \multirow{2}{*}{ Education } & Elementary school or & 166 & $40.00 \%$ \\
& below & & \\
& Middle school & 179 & $43.13 \%$ \\
& High school & 56 & $13.49 \%$ \\
& Associate college & 12 & $2.89 \%$ \\
& Bachelor's degree or & 2 & $0.48 \%$ \\
& above & & \\
\hline \multirow{2}{*}{ Monthly } & CNY 2000 or below & 121 & $29.16 \%$ \\
& CNY 200I-4000 & 156 & $37.59 \%$ \\
& CNY 400I-6000 & 104 & $25.06 \%$ \\
& CNY 600I-8000 & 31 & $7.47 \%$ \\
& CNY 800I-10,000 & 3 & $0.72 \%$ \\
& CNY 10,000 or above & 0 & $0.00 \%$ \\
\hline
\end{tabular}


people about the understandability of the questionnaire, and revised it to ensure that it was without any confusion for the elderly. Some items in the original questionnaire were deleted or merged. The revised questionnaire consists of 16 items. In the current study, Cronbach's $\alpha$ was 0.855 . See Appendix A for the complete questionnaire.

\section{Measurement of SWB}

The Memorial University of Newfoundland Scale of Happiness (MUNSH) was used to measure the SWB. The MUNSH was developed specifically for the elderly by Kozma and Stones ${ }^{43}$ and adopted by a great number of researchers in many countries for studies on the mental health of older adults. Consisting of 24 items, scores of the MUNSH range from 0 to 48, with a higher score indicating a higher level of SWB. The MUNSH was introduced into China in the late $1990 \mathrm{~s}$, and it is now one of the most commonly used SWB scales in research on Chinese older adults. $^{44}$ In the current study, Cronbach's $\alpha$ was 0.874 .

\section{Measurement of Intergenerational Support}

The Parents-Adult Children Social Support Scale ${ }^{45}$ was used to measure the level of intergenerational support that older adults receive from their adult children. The original scale is a four-point Likert scale ("never" $=1$, "rarely" = 2, "sometimes" $=3$, and "often" =4), consisting of 26 items. Since our research subjects were older adults who live alone, we revised the questionnaire by removing the items that only apply to those living with their adult children, for example, "My child prepares meals for me." The revised scale consists of 18 items; the average score of each item is the intergenerational support score. The higher the score, the higher the intergenerational support level. In the current study, Cronbach's $\alpha$ was 0.858 . See Appendix B for the revised scale.

\section{Measurement of Social Activities}

Existing questionnaires assessing Chinese older adults' social activities are mostly either neighborhood basedasking respondents how often they participate in activities that are carried out within their neighborhood (for example, playing chess), or institution based-asking about activities organized by an organization (for example, table tennis games organized by the state-owned company they retired from). However, with the rapid social development in recent years, Chinese older adults' social activities have gone far beyond the neighborhood and have begun shifting from heavily relying on institutions for organization to organizing by themselves. In light of this, we designed an eight-item questionnaire to measure the social activity level of older adults. In the current study, Cronbach's $\alpha$ was 0.776 . See Appendix C for details of the design of the questionnaire.

\section{Measurement of Self-Esteem}

The Rosenberg Self-Esteem Scale $(\mathrm{RSE})^{46}$ was used to measure the level of self-esteem. The 10-item scale is by far the most widely used instrument to measure individuals' self-esteem. ${ }^{47}$ Scores of the RSE range from 10 to 40, with a higher score indicating a higher level of self-esteem of the respondent. In the current study, Cronbach's $\alpha$ was 0.820 .

\section{Ethical Considerations}

This study was conducted in accordance with the Declaration of Helsinki. Participation in this study was voluntary. Confidentiality and anonymity were ensured in this study. Before the research, participants were told about the purpose of the survey and that information collected would be used for research purposes only. Informed consent to participate in the study was obtained from participants. The study was approved by the School of Humanities, Shanghai Institute of Technology.

\section{Results}

\section{Relationship Between WeChat Use and SWB \\ Between-Group}

SPSS (version 24.0) was used to perform statistical analyses. Among the 415 participants, 221 (53.3\%) use WeChat, while 194 (46.7\%) do not. The mean score of SWB of the WeChat users was $34.68(\mathrm{SD}=7.301)$, higher than that of the non-users, which was 32.73 (SD =7.168). The $t$-test showed that the difference was statistically significant $(t=2.741, p=0.006)$. Since a higher score means a higher level of SWB, the result suggested the SWB of WeChat users is significantly higher than that of the nonusers. Thus, H1a was supported.

\section{Within-Group}

The correlation test was performed within the user group. The results showed that, of the 221 WeChat users, proficiency in WeChat use was positively associated with SWB $(r=0.458$, $p<0.01$, suggesting that the more proficiently one uses WeChat, the higher their SWB level. Thus, H1b was supported. 
Table 2 Scores Between WeChat Users and Non-Users

\begin{tabular}{|c|c|c|c|c|c|}
\hline Variables & Group & Mean & SD & $t$ & $p$ \\
\hline $\begin{array}{l}\text { Intergenerational } \\
\text { Support }\end{array}$ & $\begin{array}{c}\text { Users } \\
\text { Non-users }\end{array}$ & $\begin{array}{l}2.712 \\
2.408\end{array}$ & $\begin{array}{l}0.304 \\
0.252\end{array}$ & I I.007 & $<0.001$ \\
\hline Social Activity & $\begin{array}{c}\text { Users } \\
\text { Non-users }\end{array}$ & $\begin{array}{l}16.10 \\
13.24\end{array}$ & $\begin{array}{l}3.450 \\
2.731\end{array}$ & 9.267 & $<0.001$ \\
\hline Self-Esteem & $\begin{array}{c}\text { Users } \\
\text { Non-users }\end{array}$ & $\begin{array}{l}27.09 \\
26.60\end{array}$ & $\begin{array}{l}2.499 \\
2.972\end{array}$ & I.797 & $=0.073$ \\
\hline
\end{tabular}

Results showed both H1a and H1b were supported. As a result, $\mathrm{H} 1$ was supported, eg, WeChat use is positively associated with the SWB of older adults living alone.

\section{Relationship Between WeChat Use and Intergenerational Support, Social Activity, and Self-Esteem \\ Between-Group}

As shown in Table 2, the user group scored significantly higher on intergenerational support than did the non-user group ( $t=11.007, p<0.001$ ), suggesting that WeChat users have a higher level of intergenerational support than the nonusers. H2a was supported. The same was observed with social activity with user group scoring significantly higher than the non-users $(t=9.267, p<0.001)$. That is, WeChat users have a higher level of social activity than the non-users.

Although the user group scored slightly higher than did the non-user group on self-esteem, the difference was not statistically significant $(t=1.817, p=0.07)$, indicating there is no statistically significant difference on self-esteem between WeChat users and non-users. Thus, H4a was rejected.

\section{Within-Group}

The correlation analysis (Table 3) showed that WeChat proficiency was positively correlated with intergenerational support $(r=0.576, p<0.01)$, indicating that the more proficient in WeChat use one is, the more intergenerational support they receive, hence $\mathrm{H} 2 \mathrm{~b}$ was supported. Results also showed that WeChat proficiency was positively correlated with social activities $(r=0.501$, $p<0.01$ ), indicating that the more proficient in WeChat use one is, the more active they are in their social life, hence H3b was supported. The Pearson's coefficient between WeChat proficiency and self-esteem was 0.011 ( $p>0.05$ ), suggesting that there is no correlation between WeChat proficiency and self-esteem and $\mathrm{H} 4 \mathrm{~b}$ was then rejected.

In the analyses above, both $\mathrm{H} 4 \mathrm{a}$ and $\mathrm{H} 4 \mathrm{~b}$ were rejected, hence $\mathrm{H} 4$ was rejected. The result suggested that the use of WeChat does not have a statistically significant effect on participants' self-esteem. We proposed self-esteem as a possible mediator because in our interviews, a number of interviewees expressed that using WeChat enables them to "catch up with the world" or "expand their views", reducing the feeling of being useless and boosting their confidence. However, the hypothesis was not supported empirically by our survey results. Even though the positive effect of selfesteem on SWB has been demonstrated by multiple studies, how an individual's self-esteem could be influenced is relatively unclear. Future research could further explore the relationship between WeChat use (or other social media) and older adults' self-esteem.

\section{Modification of the Conceptual Research Model}

The above analyses supported $\mathrm{H} 1, \mathrm{H} 2$, and $\mathrm{H} 3$ but rejected $\mathrm{H} 4$, indicating that the use of WeChat is significantly correlated with intergenerational support and social

Table 3 Pearson's Correlation Matrix

\begin{tabular}{|c|c|c|c|c|}
\hline Variables & WeChat Proficiency & Intergenerational Support & Social Activity & Self-Esteem \\
\hline WeChat Proficiency & I & & & \\
\hline Intergenerational Support & $0.576^{* *}$ & I & & \\
\hline Social Activity & $0.50 I^{* *}$ & $0.753^{* *}$ & I & \\
\hline Self-Esteem & 0.011 & $0.235^{* *}$ & $0.225 * *$ & I \\
\hline
\end{tabular}

Note: $* * p<0.01$. 


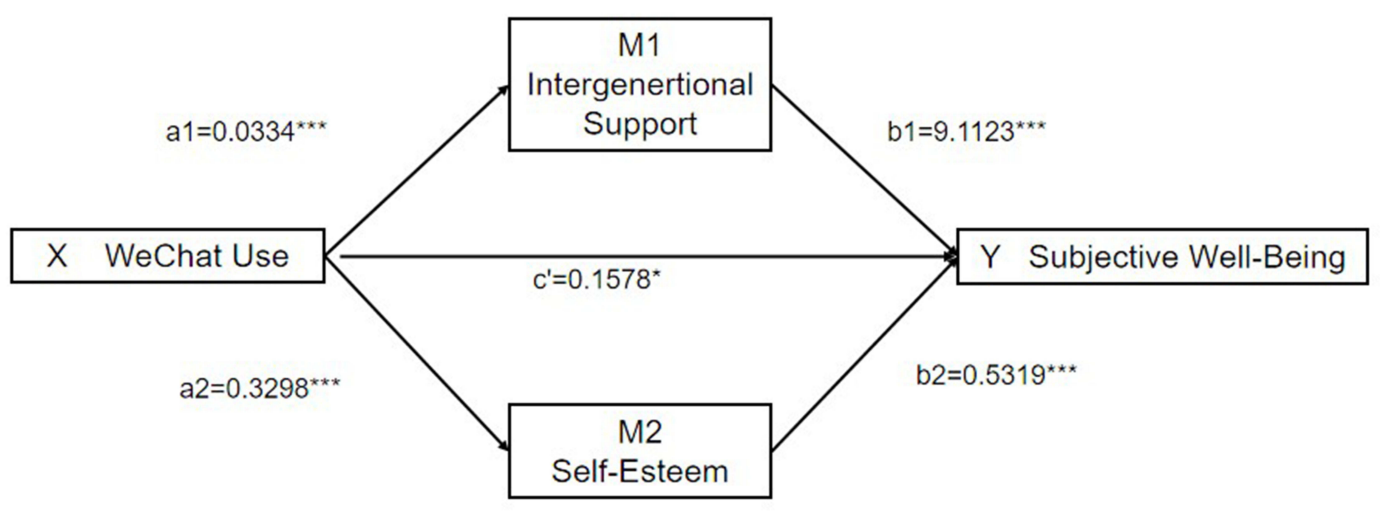

Figure 2 Test results of the modified mediation model. Notes: $* p<0.05, * * p<0.001$.

activity but not with self-esteem. As such, self-esteem should be removed from the mediation model (Figure 1). In the modified model, two parallel mediators, intergeneration support (M1) and social activity (M2), serve as the pathway linking WeChat use (X) and the SWB (Y) of older adults living alone.

The modified model was tested with PROCESS (bootstrap $=5000, \mathrm{CI}=95 \%$ ). The results demonstrate that the effects of all indirect paths of influence (a1, a2, b1, and b2 in Figure 2) were significant, but the direct path (c') yielded an effect of marginal significance (Table 4 and Figure 2).

While the total effect of WeChat use on SWB was evident, the influence of WeChat use was smaller (0.1578) with marginal significance. The mediators indirectly transmitted and amplified the influence. Of them, intergenerational support increased the effect from 0.0334 to 9.1123 (Figure 2). This finding shows that intergenerational support is the strongest mediator for explaining how SWB is perceived among elderly people.

\section{Discussion}

This study examined the relationship between WeChat use and the SWB of Chinese urban older adults living alone. The results showed that WeChat use is positively associated with the SWB level of the participants. The finding is consistent with He and Huang's study, ${ }^{48}$ which is, to our knowledge, the only research exploring the relationship between WeChat use and Chinese older adults' SWB. It' worth noting that He and Huang investigated Chinese older adults in general, not specifically those who live alone, suggesting that our results may extend to seniors of other types of living status.

In order to find out how WeChat use influences the SWB of the elderly, we examined the relationship between WeChat use and intergenerational support. The results showed there is a strong association between the two, providing new evidence to Huang ${ }^{49}$ which suggested that mobile communication tools of any kind can contribute substantially to the maintenance of the relationship between parents and their distant children. In our opinion,

Table 4 Results of the Mediation Model Test

\begin{tabular}{|c|c|c|c|c|c|c|c|c|c|c|c|c|}
\hline \multicolumn{13}{|c|}{ Consequent } \\
\hline & & \multicolumn{3}{|c|}{ MI (IGS) } & & \multicolumn{3}{|c|}{ M2 (SA) } & & \multicolumn{3}{|c|}{ Y (SWB) } \\
\hline Antecedent & & Coeff. & SE & $p$ & & Coeff. & SE & $p$ & & Coeff. & SE & $p$ \\
\hline $\mathrm{X}(\mathrm{WCU})$ & al & 0.0334 & 0.0032 & 0.000 & a2 & 0.23989 & 0.0384 & 0.000 & $c^{\prime}$ & 0.1578 & 0.0875 & $=0.073$ \\
\hline MI (IGS) & & - & - & - & & - & - & - & bl, & 9.1123 & 1.9247 & $<0.001$ \\
\hline $\mathrm{M} 2$ (SA) & & - & - & - & & - & - & - & b2 & 0.5319 & 0.1603 & $<0.001$ \\
\hline \multirow[t]{3}{*}{ Constant } & $i_{M I}$ & 2.0621 & 0.0646 & 0.001 & $\mathrm{i}_{\mathrm{M} 2}$ & 9.6720 & 0.7754 & 0.000 & $\mathrm{i}_{\mathrm{y}}$ & -1.6684 & 3.5242 & $=0.636$ \\
\hline & & \multicolumn{3}{|c|}{$R^{2}=0.3322$} & & \multicolumn{3}{|c|}{$R^{2}=0.2515$} & & \multicolumn{3}{|c|}{$R^{2}=0.4387$} \\
\hline & & \multicolumn{3}{|c|}{$F(1,219)=198.966, p<0.001$} & & \multicolumn{3}{|c|}{$F(I, 219)=73.578, p<0.001$} & & \multicolumn{3}{|c|}{$F(I, 219)=56.5436, p<0.001$} \\
\hline
\end{tabular}


WeChat is especially instrumental because of its multifunctionality and ease of use. As one of the participants disclosed to us, before using WeChat, the only way to contact her daughter who works in Shanghai was through cell phone calls. "But you couldn't give her a call anytime you miss her. That would disturb her work. Furthermore, there wasn't much to talk about if I called her too often." she noted. Now, with WeChat, she can send her daughter messages almost at any time and she can reply right away or wait until she finishes her work if it's not an emergency. Also, her daughter often sends her pictures of her daily life -her breakfast, her new clothes or haircut, the office building where she works ... .... Communication via WeChat has now become a daily routine of them. Besides text or voice communication, sending digital "red envelopes" (a Chinese tradition of putting money in red envelopes as gifts) to parents through WeChat on special occasions (such as parents' birthdays) is an efficient and novel way to provide parents both financial and emotional support. ${ }^{50}$ With WeChat, intergenerational support would be a lot easier to fulfill.

This study also examined the relationship between WeChat use and social activities of the elderly as another mediator linking WeChat use and SWB. Evidence abounds that social activities have multiple benefits for older adults. This might be particularly true for those who live alone given that they may have less interaction with others within their homes. Chan et al found that older adults living alone are more likely to be socially isolated and may benefit more from social activities. ${ }^{51}$ WeChat is a tool well suited for the elderly to organize social activities. Before WeChat was introduced, people relied heavily on cell phone calls and text messages to organize such activities. However, one-to-one phone calls are inefficient if the activity involves many people with different preferences. With WeChat's "group chat" function, which allows as many as 500 people to group chat in one dialogue box, it is a lot easier to organize activities, allowing older adults to be much more active than before. Besides, other functions, for example "location sharing", are of great use in facilitating social activities, potentially increasing their willingness to participate.

\section{Practical Implications}

First, for policy makers, this study provides useful information regarding the effect of WeChat use (and perhaps other internet applications) on older adults. Chinese government has realized that the lack of digital literacy not only poses challenges to the older adults, but also hinders the overall development of the society. On November 24, 2020, the General Office of the State Council issued a guideline to address the problem which stipulates that by the end of 2022, long-term mechanisms bridging the digital divide will be established. ${ }^{52}$ It is expected that more plans to help the elderly improve digital literacy will be proposed afterwards. Our study could serve as a part of scientific basis for policy-making.

Second, for the older adults, our study could be deemed as a statement: Unlike the dishwasher or digital camera which could save you some time or bring you some joy if you use them but also totally OK if you do not, WeChat, as well as some other internet-based applications, has been increasingly integrated into all aspects of the society to the extent that some scholars view WeChat as "an infrastructure for China". ${ }^{53}$ If you do not use WeChat, it is unlikely that you can go about your daily life without encountering any trouble. Older adults must realize the necessity of including themselves into the digital world. Furthermore, they should make great effort to explore the multiple benefits of digitization to promote successful aging. Do not use age as an excuse to distance yourself from modern technologies. As Knowles and Hanson pointed out, the notion that aging per se leads to technology abandonment does not withstand scrutiny. ${ }^{54}$

Third, the children of older adults, whether living with or away from their parents, should provide more technical support to your parents. Chinese tradition places a lot of emphasis on caring for the elderly or what we call "filial piety". However, filial piety is largely expressed by caring about parents' health conditions. In modern society, it very necessary for younger adults to expand their understanding of filial piety to include many other areas that may influence their parents' well-being. Our study showed that WeChat use is significantly associated with SWB of older adults living alone (and perhaps those who live with family members). Adult children should take teaching their parents how to use WeChat and other internet skills as their responsibility. It is of special importance for younger adults who do not live with their parents since they are not able to provide immediate support. As such, they should make good use of the time when they are together to teach their parents these important digital skills. Additionally, according to Zhou's study, the more time children spend teaching their parents digital knowledge, the more harmonious the family will be. ${ }^{55}$ 


\section{Theoretical Contributions}

As noted in the introduction, studies on the relationship between WeChat use and SWB of older adults are very scant. Against the backdrop of the co-occurrence of population aging and society digitization, our study contributed to the bridging of the literature gap. Secondly, our study focused on older adults living alone, a group which were previously studied from viewpoints that usually reveal the vulnerability of them. Our study demonstrated a possibility that living conditions of this disadvantaged group could be considerably improved through the use of WeChat, thus adding new perspective to the research of the older adults living alone.

\section{Limitations and Future Work}

As with most studies, the present study has some limitations that need to be discussed. First, survey participants were mainly selected from the investigators' own networks, resulting in a certain degree of sampling bias. Second, SWB is a highly sophisticated concept that could be influenced by many factors, even those that have yet to be identified or conceptualized by scholars. Our study proposed two mediators, but it does not mean that they are the only variables that mediate WeChat use and SWB. Different studies could propose different mediators to explain how SWB could be influenced by the use of certain social media, thus providing more perspectives on research in this field.

\section{Conclusion}

This study aimed to examine the effect of WeChat use on the SWB of Chinese urban older adults living alone and how the effect could occur. Results suggested that WeChat use is positively associated with SWB of the elderly. Findings also showed that the relationship between WeChat use and SWB is mediated by intergenerational support and social activities. That is to say, WeChat use by Chinese older adults living alone increases their intergenerational support and social activities; the increased intergenerational support and social activities then enhances their SWB.

\section{Acknowledgments}

The authors are thankful to all the participants. And special thanks to the eight investigators who endeavored to make sure the survey was completed with high quality.

\section{Funding}

This study was supported by Shanghai Sailing Program backed by Shanghai Science and Technology Committee (20YF1447400).

\section{Disclosure}

The authors report no conflicts of interest in this work.

\section{References}

1. Verduyn P, Ybarra O, Résibois M, Jonides J, Kross E. Do social network sites enhance or undermine subjective well-being? A critical review. Soc Issues Policy Rev. 2017;11(1):274-302. doi:10.1111/ sipr. 12033

2. Statista. Number of monthly active WeChat users from 2nd quarter 2011 to 1st quarter 2021. Available from: https://www.statista.com/ statistics/255778/number-of-active-wechat-messenger-accounts/. Accessed June 10, 2021.

3. Dong L, Zhang Y, Xu Z, Chu D, Sheng L. Exploiting information diffusion feature for link prediction in Sina Weibo. Sci Rep. 2016;6:20058. doi:10.1038/srep20058

4. Arjun K. Everything you need to know about WeChatChina's billion-user messaging app. Available from: https://www. cnbc.com/2019/02/04/what-is-wechat-china-biggest-messaging-app. html. Accessed June 10, 2021.

5. Hu Y. Ten years history of WeChat. Available from: https://www.163. com/dy/article/G07DQ52A0511UL0E.html. Accessed June 12, 2021.

6. Miao W, Huang Y. Re-domesticating social media when it becomes disruptive: evidence from China's "super app" wechat. Mob Media Commun. 2020;9(9):1-18. doi:10.1177/2050157920940765

7. The Economist. Mark Zuckerberg wants to build WeChat for the West; 2019. Available from: https://www.economist.com/business/ 2019/04/30/mark-zuckerberg-wants-to-build-wechat-for-the-west. Accessed August 29, 2021.

8. The New York Times. Mark Zuckerberg wants Facebook to Emulate China's WeChat. Can it?; 2019. Available from: https://www.nytimes. com/2019/03/07/technology/facebook-zuckerberg-wechat.html. Accessed August 29, 2021.

9. Tencent. Annual report 2016. Available from: https://tech.qq.com/a/ 20161228/018057.htm $\# \mathrm{p}=2$. Accessed May 2, 2021.

10. Tencent. Annual report 2018. Available from: https://support.weixin. qq.com/cgi-bin/mmsupport-bin/getopendays. Accessed May 2, 2021.

11. National Bureau of Statistics. Report of the 7th National Census; 2021. Available from: http://www.stats.gov.cn/tjsj/tjgb/rkpcgb/. Accessed August 29, 2021.

12. Quadagno JS. Aging and the Life Course: An Introduction to Social Gerontology. New York: McGraw-Hill Education; 2006.

13. Gao YP, Hu JS, Xiao J. Gerontological Psychology. Beijing: Peking University Press; 2013. In Chinese.

14. Treiman DJ. The "difference between heaven and earth": urban-rural disparities in well-being in China. Res Soc Stratif Mobil. 2012;30 (1):33-47. doi:10.1016/j.rssm.2011.10.001

15. Zhou RS, Pan ZD, Xie B, Cai J.Comparison of mental health and subjective well-being between empty-nesters and non-empty-nesters in Huangpu District, Shanghai. Shanghai Arch Psychiatry. 2009;21 (6):336-339.

16. Li DM, Chen TY, Wu ZY, Xiao JF, Fei AH. Study on the physiological and psychological health of the urban elderly. Chinese J Gerontol. 2006;26:1314-1316.

17. Huang JC. Older adults living alone in China: a research review. Chin $J$ Gerontol. 2015;35(23):6954-6956. doi:10.3969/j.issn.10059202.2015.23.142 
18. Zhao Y Assessing self-neglect on elderly, exploring its impact factors and the impact on their quality of life in rural China [doctoral dissertation]. China: Anhui Medical University;2017.

19. Yu M, Gu L, Jiao W, Xia H, Wang W. Predictors of self-neglect among community-dwelling older adults living alone in China. Geriatr Nurs. 2019;40(5):457-462. doi:10.1016/j.gerinurse.2019.02.002

20. Cobb S. Social support as a moderator of life stress. Psychosom Med. 1976;38(5):300-314. doi:10.1097/00006842-197609000-00003

21. Peng H, Mao X, Lai D. East or west, home is the best: effect of intergenerational and social support on the subjective well-being of older adults: a comparison between migrants and local residents in Shenzhen, China. Ageing Int. 2015;40:376-392. doi:10.1007/s12126015-9234-2

22. Mohd TAMT, Yunus RM, Hairi F, Hairi NN, Choo WY. Social support and depression among community dwelling older adults in Asia: a systematic review. BMJ Open. 2019;9(7):e026667. doi:10.1136/bmjopen-2018-026667

23. Tang D, Zou J, Shen JL, Zhang L. The influence factors of subjective well-being in older adults. Chinese Mental Health $J$ 2006;20:160-162.

24. Ren J, Jin ZC, Yang QJ. A meta-analysis of factors affecting subjective well-being of the elderly in China. Chin J Clin Psychol. 2010;18:119-121.

25. Zhang HK. The present situation and change of the education level of the elderly population in China. Chinese $J$ Gerontol. 2016;36:1215-1216.

26. Murrell SA, Meeks S, Walker J. Protective functions of health and self-esteem against depression in older adults facing illness or bereavement. Psychol Aging. 1991;6(3):352-360. doi:10.1037// 0882-7974.6.3.352

27. Alaphilippe D. Self-esteem in the elderly. Psychol Neuropsychiatr Vieil. 2008;6(3):167-176. doi:10.1684/pnv.2008.0135

28. Yao P. Relationship between well-being, exercise and self-esteem in the elderly. Yinshan Acad J. 2018;32:41-44.

29. Song FF. A study on the relationship between older adults' selfesteem and their subjective well-being. Stat Manage. 2016;7:50-52.

30. Valenzuela S, Park N, Kee KF. Is there social capital in a social network site?: Facebook use and college students' life satisfaction, trust, and participation. J Comput Mediat Comm. 2009;14 (4):875-901. doi:10.1111/j.1083-6101.2009.01474.x

31. Pittman M, Reich B. Social media and loneliness: why an Instagram picture may be worth more than a thousand Twitter words. Comput Hum Behav. 2016;62:155-167. doi:10.1016/j.chb.2016.03.084

32. Apaolaza V, Hartmann P, Medina E, Barrutia JM, Echebarria C. The relationship between socializing on the Spanish online networking site Tuenti and teenagers' subjective wellbeing: the roles of selfesteem and loneliness. Comput Hum Behav. 2013;29(4):1282-1289. doi:10.1016/j.chb.2013.01.002

33. Baumeister RF, Leary MR. The need to belong: desire for interpersonal attachments as a fundamental human motivation. Psychol Bull. 1995;117(3):497-529. doi:10.1037/0033-2909.117.3.497

34. Mcauley E, Blissmer B, Marquez DX, Gerald JJ, Arthur FK, Jeffrey K. Social relations, physical activity, and well-being in older adults. Prev Med. 2000;31(5):608-617. doi:10.1006/pmed.2000.0740

35. Vitak J, Ellison NB. 'There's a network out there you might as well tap': exploring the benefits of and barriers to exchanging informational and support-based resources on Facebook. New Media Soc. 2012;15(2):243-259. doi:10.1177/1461444812451566

36. Holton AE, Chyi HI. News and the overloaded consumer: factors influencing information overload among news consumers. Cyberpsychol Behav Soc Netw. 2012;15(11):619-624. doi:10.1089/ cyber.2011.0610
37. Sagioglou C, Greitemeyer T. Facebook's emotional consequences: why facebook causes a decrease in mood and why people still use it. Comput Human Behav. 2014;35:359-363. doi:10.1016/j. chb.2014.03.003

38. Burke M, Marlow C, Lento TM Social network activity and social well-being. Proceedings of the 28th International Conference on Human Factors in Computing Systems, CHI 2010, Atlanta, Georgia, USA, April 10-15. . ACM; 2010. doi: 10.1145/ 1753326.1753613.

39. Verduyn P, Lee DS, Park J, Shablack H, Orvell A, Bayer J. Passive facebook usage undermines affective well-being: experimental and longitudinal evidence. J Exp Psychol Gen. 2015;144(2):480-488. doi:10.1037/xge0000057

40. Frison E, Eggermont S. Toward an integrated and differential approach to the relationships between loneliness, different types of facebook use, and adolescents 'depressed mood. Commun Res. 2015;47(5):701-728. doi:10.1177/0093650215617506

41. Baltes PB, Smith J. New frontiers in the future of aging: from successful aging of the young old to the dilemmas of the fourth age. Gerontology. 2003;49(2):123-135. doi:10.1159/000067946

42. Tencent Research Institute. The Elderly's WeChat Life. Hang Zhou: Zhejiang Publishing United Group; 2018.

43. Kozma A, Stones MJ. The measurement of happiness: development of the memorial university of newfoundland scale of happiness (MUNSH). J Gerontol. 1980;35(6):906-912. doi:10.1093/geronj/ 35.6.906

44. Chen Z, Davey G. Happiness and subjective well-being in mainland China. J Happiness Stud. 2008;9(4):589-600. doi:10.1007/s10902008-9092-7

45. Wang DH, Tong Y, Zhou LQ, Shen JL. Mechanisms between intergenerational social support and subjective well-being of the elderly. Acta Psychologica Sinica. 2004;36:78-82.

46. Rosenberg M. Society and the Adolescent Self-Image. Princeton: Princeton University; 1965.

47. Robins RW, Hendin HM, Trzesniewski KH. Measuring global self-esteem: construct validation of a single-item measure and the Rosenberg self-esteem scale. Pers Soc Psychol Bull. 2001;27 (2):151-161. doi:10.1177/0146167201272002

48. He JP, Huang XX. WeChat use and subjective well-being of urban elderly: mediated by social capital. J Mass Commun. 2020;8:57-66.

49. Huang LY. A study on the relationship between mobile communication tools and distant parent-child intimacy. Southeast Commun. 2017;10:40-46.

50. Zhou YQ. The rising of digital vulnerable group: the influential factors of Wechat adoption and use among senior citizens. J Commun. 2018;7:66-86.

51. Chan E, Procter-Gray E, Churchill L, Cheng J, Li W. Associations among living alone, social support and social activity in older adults. AIMS Public Health. 2020;7(3):521-534. doi:10.3934/publichea lth. 2020042

52. The General Office of the State Council. State Council vows better services for the elderly; 2020. Available from: http://www.gov.cn/ zhengce/content/2020-11/24/content_5563804.htm. Accessed August 29, 2021.

53. Plantin JC, Seta GD. Wechat as infrastructure: the techno-nationalist shaping of Chinese digital platforms. Chin J Commun. 2019:1-17. doi:10.1080/17544750.2019.1572633

54. Knowles B, Hanson VL. The wisdom of older technology (non) users. Commun ACM. 2018;61(3):72-77. doi:10.1145/3179995

55. Zhou YQ. A comparative study on digital skills between the parents and teen children. Modern Communication. 2014;2:123-129. 


\section{Publish your work in this journal}

Psychology Research and Behavior Management is an international, peer-reviewed, open access journal focusing on the science of psychology and its application in behavior management to develop improved outcomes in the clinical, educational, sports and business arenas. Specific topics covered in the journal include: Neuroscience, memory and decision making; Behavior modification and management; Clinical applications; Business and sports performance management; Social and developmental studies; Animal studies. The manuscript management system is completely online and includes a very quick and fair peer-review system, which is all easy to use. Visit http://www. dovepress.com/testimonials.php to read real quotes from published authors. 